\title{
IN SITU HVEM STUDY OF ION IRRADIATION-INDUCED GRAIN GROWTH IN AU THIN FILMS*
}

\author{
Joyce C. Liu, Jian Li and J. W. Mayer \\ Department of Materials Science and Engineering \\ Cornell University, Ithaca, NY 14853 \\ Charles W. Allen and Lynn E. Rehn \\ Materials Science Division \\ Argonne Natiorial Laboratory \\ Argonne, Illinois 60439
}

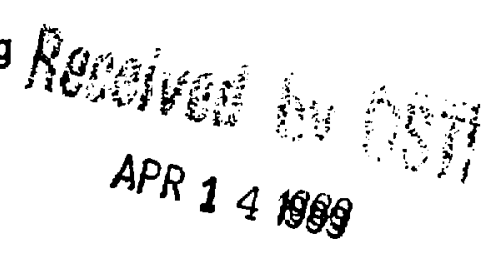

CONF-881155--63

DE89 009856

\begin{abstract}
January 1989

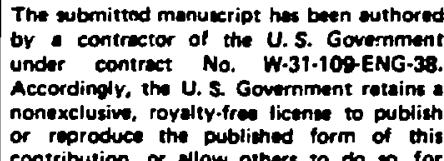

\section{DISCLAIMER}

\begin{abstract}
This report was prepared as an account of work sponeored by an agency of the United States Government. Neither the United States Guvernment nor any agency thereof, nor any of their employees, makes any warranty, express or implied, or assumes any legal liability or responsibility for the accuracy, completeness, or usefulness of any information, apparatus, product, or process disclosed, or represents that its use would not infringe privately owned rights. Reference herein to any specific commercial product, process, or service by trade name, trademark, manufacturer, or otherwise does not necessarily constitute or imply its endorsemen' recommendation, or favoring by the United States Government or any agency thereof. The views and opinions of authors expressed herein do not necessarily state or reflect those of the United States Government or any agency thereof.
\end{abstract}

Paper presented at the 1988 MRS Fall Meeting, November 28-December 2, 1988, Boston, MA.

*The Cornell work was supported in part by the National Science Foundation (John Hurt) and the Argonne effort by the U. S. Department of Energy, BESMaterials Sciences, under Contract H-31-109-Eng-38.

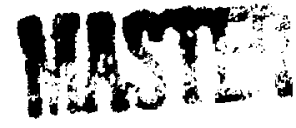




\section{IN SITU HVEM STUDY OF ION IRRADIATION-INDUCED GRAIN GROWTH \\ IN AU THIN FILMS}

JOYCE C. LIU, JIAN LI AND J. W. MAYER

Department of Materials Science and Engineering, Cornell University, Ithaca, NY 14853; CHARLES W. ALLEN AND LYNN E. REHN

Materials Science Division, Argonne National Laboratory, Argonne, IL 60439

\section{ABSTRACT}

In situ observations of $1.5 \mathrm{MeV} \mathrm{Xe}^{+}$ion irradiated Au films at room temperature and at $150^{\circ} \mathrm{C}$ reveal the evolution of grain growth: the average grain size increases by the mechanisms of grain boundary migration and grain coalescence.

\section{INTRODUCTION}

Ion irradiation induced grain growth has been observed in several materials, including $N i$, $A u$, Si and $G e[1,2,3,4]$. Similar to investigations of thermally induced grain growth, the objective is to establish a relationship between grain size and irradiation time or betwęen grain size and ion dose when the dose rate is constant. Results from $\mathrm{Ag}^{+}$implanted $\mathrm{Ni}$ thin films $[1,2]$ show that the average grain diameter is proportional to the ion dose. For $\mathrm{Au}, \mathrm{Si}$, and $\mathrm{Ge}$, it is found, however, that the increase of grain size with the dose exhibits a power law dependence [3]. Since previous studies of ion irradiation induced grain growth are all based on observation following irradiations $[1,2,3,4]$, a direct observation of the ion irradiation induced grain growth is useful for understanding the mechanism, kinetics and driving force of this process. The evolution of grain growth in ion irradiated Au thin films is observed in an electron microscope, and some of the results are discussed in the present paper.

\section{EXPERIMENTAL PROCEDURE}

Au films with thickness $\sim 55 \mathrm{~nm}$ were prepared by sputter deposition on $\mathrm{NaCl}$ substrates. The grain size distribution is uniform and the average size is about $25 \mathrm{~nm}$. Moreover, grains in the as-deposited films were

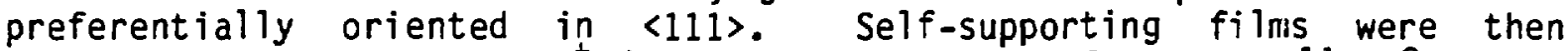
irradiated with $1.5 \mathrm{MeV} \mathrm{Xe}^{+}$ions at a dose rate of $1.7 \times 10^{11} / \mathrm{cm}^{2} . \mathrm{sec}$ to minimize $x e$ implantation in the films and the effect of beam heating. The experiments were carried out at the HVEM-Tandem User Facility at Argonne National Laboratory [5], where a $2 \mathrm{MeV}$ Tandem accelerator is interfaced to an AEI EM-7 1.2 MV high voltage transmission electron microscope (HVEM). The ion beam is introduced into the HVEM via a $33^{\circ}$ ion-beam access tube; i.e., the ion beam is $33^{\circ}$ from the electron beam in the microscope. During irradiations at room temperature and $150^{\circ} \mathrm{C}$, microstructural changes of the films are examined in situ with the HVEM operated at $500 \mathrm{kV}$. The evolution of grain growth is followed by recording the images continuously on video tape and sequentially on photographic film.

\section{OBSERVATIONS AND DISCUSSION}

\section{Direct observations}

Direct observation of the Au films during ion irradiation reveal a dynamic picture of the induced grain growth; i.e., a gradual increase of average grain size is associated with dynamic changes in lattice defect structures. Although individual defects were not resolved due to their high density, the change of defect structure is suggested by the continuous 
change of contrast in different areas of a sirigle grain during irradiation. An example of the evolution of a single grain is shown in the dark field images of Fig. 1. The observed defects are presumed to be dislocation loops, since it has been previously reported that high concentration of vacancies in a collision cascade can collapse to form dislocation loops under irradiation at room temperature $[6,7]$. Such Frank loops can expand by climb or become glissile when converted to prismatic loops by unfaulting. The observed contrast change due to dislocation rearrangement during ion irradiation, therefore, can be attributed to interactions of point defects and dislocations, dislocations with one another, dislocations and grain boundaries and dislocations and the free surfaces. The excess point defect concentration accelerates atom diffusion. Dislocation movement to grain boundaries can in turn cause structure changes in boundaries and thus affect grain boundary migration and grain orientation. The actual role of dislocations in the radiation-induced grain growth process is not clear, however, and certainly warrants further study.

Growth by grain boundary migration

Dark field images of the Au films irradiated with $1.5 \mathrm{MeV} \mathrm{Xe}^{+}$at $150^{\circ} \mathrm{C}$ and room temperature are shown in Fig. 2 and Fig. 3, respectively. The images cover a dose range from $5.4 \times 10^{13}$ to $5.1 \times 10^{14} / \mathrm{cm}^{2}$ for the $150^{\circ} \mathrm{C}$ irradiation, and from $1.7 \times 10^{14}$ to $5.1 \times 1014 / \mathrm{cm}^{2}$ for the room temperature irradiation. It is noticed that the majority of the grains in the films are larger than the film thickness which is about $55 \mathrm{~nm}$, so that the consecutive images demonstrate the evolution of 2-dimensional growth at both temperatures. Following grain "d" in Fig. 2 very closely, we noticed that after an irradiation of $5.4 \times 1013 \times \mathrm{e}^{+} / \mathrm{cm}^{2}$ the grain had an irregular shape with diameter approximately equal to $110 \mathrm{~nm}$. As the dose had increased from $5.4 \times 10^{13}$ to $1.1 \times 10^{14} \times \mathrm{e}^{+} / \mathrm{cm}^{2}$, the size of this grain increased about $30 \%$ by consuming its surrounding smaller grains. Then, the grain shape became hexagonal by continuous consumption of neighboring grains. At

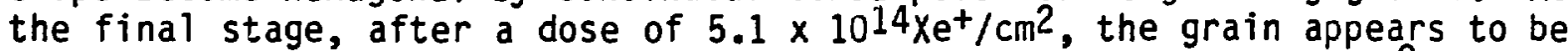
a hexagon with sides of almost equal length and angles about $120^{\circ}$ at the vertices. Similar development is found in Fig. 3 for grain " $D$ " irradiated at room temperature.

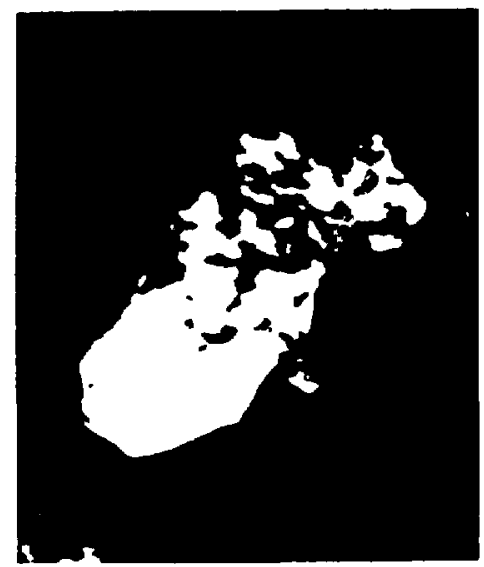

$2.6 \times 10^{14} / \mathrm{cm}^{2}$

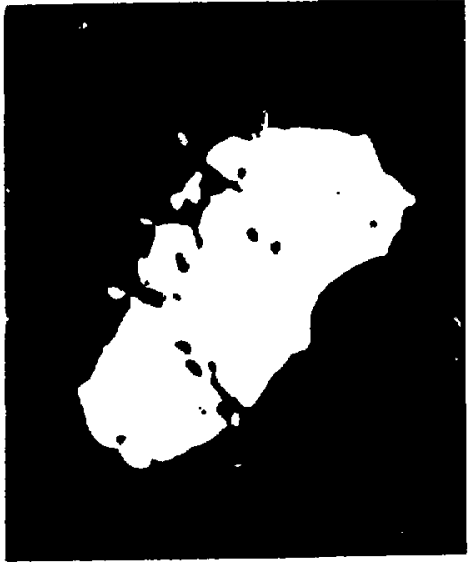

$5.1 \times 10^{14} / \mathrm{cm}^{2}$ 


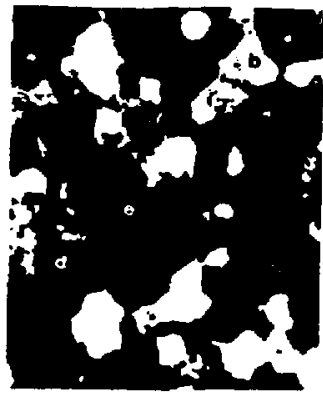

$5.4 \times 10^{13} / \mathrm{cm}^{2}$

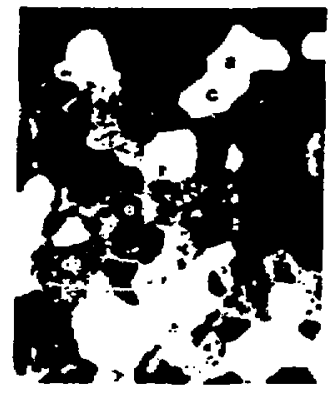

$1.1 \times 10^{14} / \mathrm{cm}^{2}$

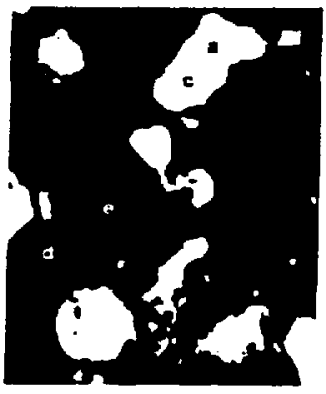

$1.7 \times 10^{14} / \mathrm{cm}^{2}$

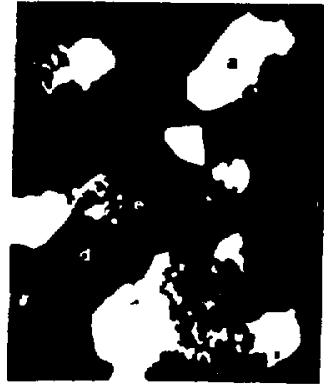

$2.6 \times 10^{14} / \mathrm{cm}^{2}$

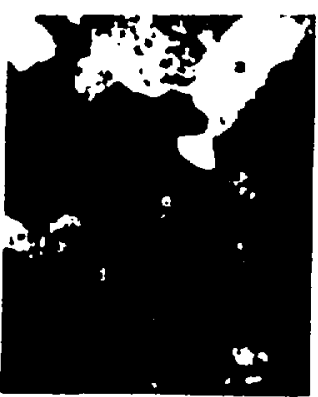

$5.1 \times 10^{19} / \mathrm{cm}^{2}$

$$
\stackrel{\longmapsto}{100 \mathrm{~nm}}
$$

$1.5 \mathrm{MeV} \mathrm{Xe}_{e}^{+}$irrodioled Au of $150^{\circ} \mathrm{C}$

Fig. 2. Dark field images of Au films irradiated by $1.5 \mathrm{MeV} \mathrm{Xe}{ }^{+}$at $150^{\circ} \mathrm{C}$ with doses from $5.4 \times 10^{13}$ to $5.1 \times 10^{14} / \mathrm{cm}^{2}$.

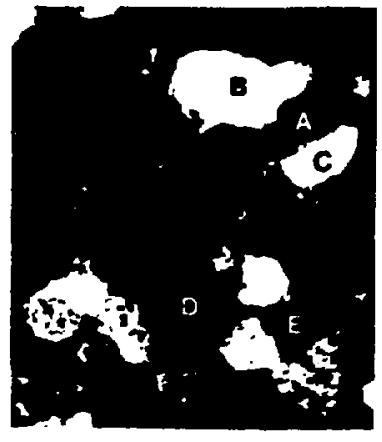

$1.7 \times 10^{14} / \mathrm{cm}^{2}$

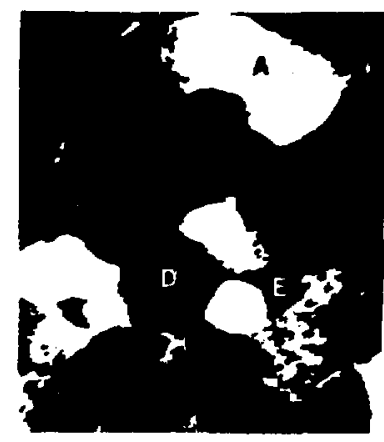

$3.4 \times 10^{14} / \mathrm{cm}^{2}$

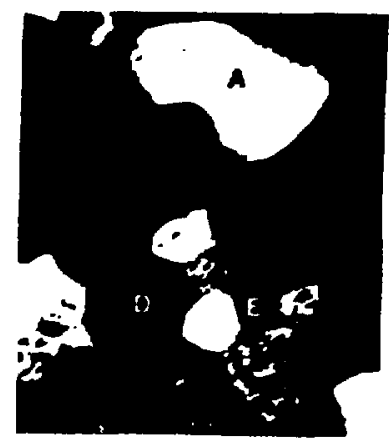

$5.1 \times 10^{14} / \mathrm{cm}^{2}$

$\stackrel{\longmapsto}{100 \mathrm{~nm}}$

I.5 MeV Xe ${ }^{+}$irradiated Au at room temp

Fig. 3. Dark field images of Au fi]ms irradiated by $1.5 \mathrm{MeV} \mathrm{Xe}^{+}$at room temperature with doses from $1.7 \times 10^{14}$ to $5.1 \times 10^{14} / \mathrm{cm}^{2}$. 
The evolution of grains " $d$ " and " $D$ " represents a process of grain enlaryement during the ion irradiation. In parallel, a process of grain shrinkage is also revealed. The grain labeled "e" in Fig. 2 had a size of $55 \mathrm{~nm}$ after irradiation with $5.4 \times 1013 \times \mathrm{e}^{+} / \mathrm{cm}^{2}$. Afterward, its dimension did not change significantly with the ion dose until its neighboring grains became relatively larger. According to Fig. 2, the transition took place

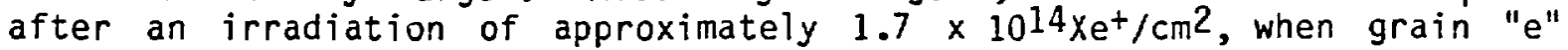
with concave boundaries was surrounded by three larger grains. When the dose was further increased to $5.4 \times 10^{17} / \mathrm{cm}^{2}$, the size of grain "e" was reduced to only $18 \mathrm{~nm}$. Similarly, the shrinkage of grain "E" in Fig. 3 is also observed.

The change of morphology in this irradiated Au film resembles the twodimensional grain growth described by Hillert [8] in his defect model, where an array of hexagons is defined as perfect structure. If a defect, e.g., a 5-side grain, is introduced into a perfect array, grain boundary migration tends to occur because of the free energy difference caused by the curved boundaries. Therefore, the in situ observations of the evolution of grains, such as the shrinkage of small grains with concave boundaries and the development of stable hexagonal structures, in the irradiated $A u$ films indicates that the main driving force of grain growth during irradiation is reduction of grain boundary energy. Further, the grain growth in these particular areas is accomplished by the gradual migration of grain boundaries towards grains with higher free energy without any formation of nuclei.

Grain coalescence

Besides the observed grain boundary migration, it is also noticed that the contrast between some grains varies during the irradiations. Such evidence can be found in Figs. 2, and 3 of the irradiated Au films. For instance, in Fig. 2 after an irradiation of $5.4 \times 10^{13} \times \mathrm{e}^{+/} \mathrm{cm}^{2}$ grain "a" was distinguished from grain " $b$ " by the contrast, and it was separated from grain "c" by a boundary which was decorated with dislocations. As the dose increased to $1.1 \times 10^{14} / \mathrm{cm}^{2}$, the sharp boundary between the original grains "a" and "b" disappeared, causing a dramatic change of the geometric shape of grain "a". At this point, the boundary between grain "a" and "e" was still present, which was determined not only by the contrast but also by the existing vertices on both ends as a result of balancing the surface tension of relevant boundaries. As the irradiation continues, the boundary between grains " $a$ " and " $c$ " gradually faded av'ay by a dose of 5.1 $x 1014 / \mathrm{cm}^{2}$. The absence of that grain boundary is confirmed by the straightening of the relevant boundaries between the coalesced grain and its neighboring grains. Moreover, the contrast between grains "a" and " $c$ " became less, indicating the two grains merged into the same orientation. It is further displayed from these micrographs that the contrast between this coaiesced region relative to its surrounding grains has changed during the irradiation, which could be caused by a relative orientation change between this area and the neighboring grains or between the film and the incident electron beam. The same grain coalescence process is observed at room temperature from the merging of grains " $A, B, C^{\prime \prime}$ in Fig. 3.

In a previous study of thermal annealing behavior of cold rolled $3 \%$ silicon-iron single crystal, Hu [9] observed in an electron microscope that recrystallized nuclei could be formed by coalescence of subgrains in a high dislocation density area. He also noticed that the orientation of the coalesced grain differed from that of the original subgrains from which it was formed. A schematic diagram of this coalescence process is given in Fig. 4 by Li [10]. At the initial stage (Fig. 4(a)), the two grains are misoriented by a small angle. During thermal annealing the low-angle boundary "CH" is eliminated by dislocation climb along this boundary and by a relative rotation of the two grains, which is achieved by short-range 


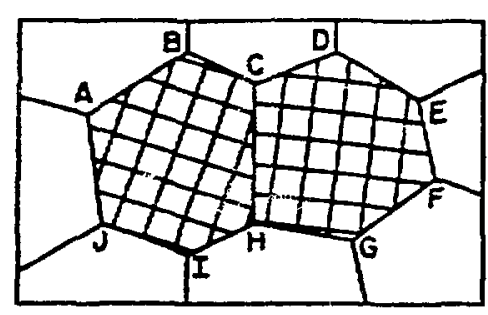

(a)

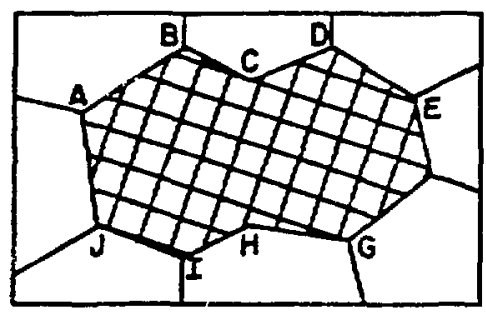

(c)

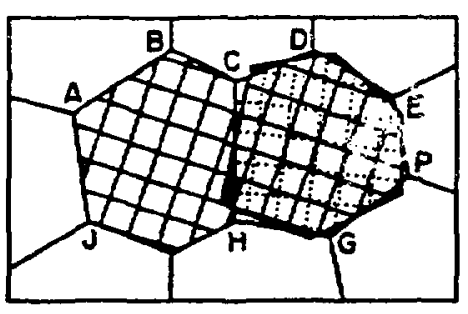

(b)

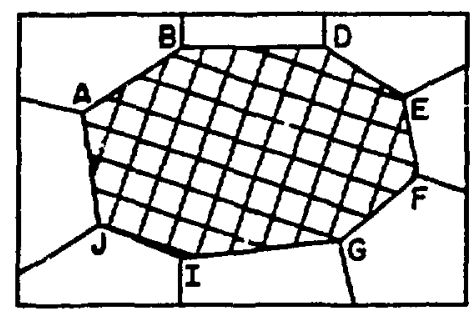

(d)

Fig. 4 Schematic representation of subgrain coalescence: (a) original structure; (b) rotation of one grain; (C) coalesced subgrain and (d) rearrangement of affected boundaries. (After Li, Ref. [10])

aiffusion of atoms along the boundaries from the shaded to unshaded areas (Fig. $4(b))$. Then, the affected boundaries of the coalesced grain are rearranged to remove the unstable angles (Fig. $4(\mathrm{c})$ and (d)). According to his description, the coalescence of subgraifs during thermal annealing is very similar to the merging of some grains in the irradiated films.

Due to the relatively low surface energy, the grains with $\langle 111\rangle$ normal to the surface of the irradiated Au films are thermodynamicaliy more favored than grains with other orientations. Since the grain coalescence takes place at low-angle grain boundaries, it is suggested that the grain coalescence is significant only in a process of two-dimensional grain growth where a fair number of grains are oriented in <111> and share lowangle boundaries. Because grain growth by coalescence is not the only mechanism of grain enlargement in the irradiated films, satisfactory kinetic data for this process were not obtained.

\section{SUMMARY}

In situ observations of $1.5 \mathrm{MeV} \mathrm{Xe}^{+}$ion irradiated Au films at room temperature and at $150^{\circ} \mathrm{C}$ reveal the evolution of grain growth. In the process of two-dimensional growth, the average grain size increases by the mechanisms of grain boundary migration and grain coalescence.

\section{ACKNOWLEDGMENTS}

The Cornell work was supported in part by the National Science Foundation (John Hurt) and the Argonne effort by the U. S. Department of Energy, Basic Energy Sciences--Materials Sciences, under Contract W-31-109-Eng-38. The assistance of Loren Funk and Edward Ryan of Argonne National Laboratory is gratefully acknowledged. 
[1] P. Wang, D. A. Thompson and W. W. Smeltzer, Nucl. Instrum. Methods B7/8, 97 (1985).

[2] P. Wang, D. A. Thompson and W. W. Smeltzer, Nucl. Instrum. Methods B16, 288 (1986).

[3] H. A. Atwater, H. I. Smith and C. V. Thompson, in Beam-Solid Interactions and Phase Transformations, edited by H. Hurz, G. L. Olson and J. M. Poate (Materials Research Society, Pittsburgh, PA, 1986), Vol. 51, p. 337

[4] H. A. Atwater, C. V. Thompson and H. I. Smith, J. Appl. Phys. 64, 2337 (1988).

[5] A. Taylor, C. W. Allen, and E. A. Ryan, Nucl. Instrum. Methods, B24/25, 598 (1987).

[6] W. Jager, J. Microsc. Spectrosc. Electron. 6, 437 (1981).

[7] M. A. Kirk, I. M. Robertson, M. L. Jenkins, C. A. English, T. J. Black, and J. S. Vetrano, J. Nucl. Mater. 149, 21 (1987).

[8] M. Hillert, Acta Metal1. 13, 227 (1965).

[9] $H$. Hu in Electron Microscopy and Strength of Crystals, edited by $G$. Thomas and J. Washburn (Interscience, New York, 1963) p. 546.

[10] J. C. M. Li, J. Appl. Phys. 33, 2958 (1962). 